\title{
CONTRIBUIÇÃO AO ESTUDO DA BIOQUÍMICA CLÍNICA SÉRICA EM CABRAS LEITEIRAS (Capra hircus) CRIADAS NA REGIÃO METROPOLITANA DE CURITIBA - PR.
}

E.M.S. SCHMIDT ${ }^{1}$; R. LOCATELLI-DITTRICH ${ }^{2}$;.R. BARROS FILHO ${ }^{3}$; M.E. SAITO ${ }^{4}$; R.M.V. MANGRICH ${ }^{5}$; S.F.C. SILVA ${ }^{6}$; E.M.G. CIFFONI ${ }^{7}$;.C. PENSO $^{8}$

${ }^{1}$ Professores do Departamento de Medicina Veterinária - Universidade Federal do Paraná. ${ }^{2}$ Acadêmicas do Curso de Medicina Veterinária - Universidade Federal do Paraná. ${ }^{3}$ Aluna do Curso de Pós-Graduação em Biologia Celular Universidade Federal do Paraná. ${ }^{4}$ Professora de Doenças Infecciosas da UNIPAR/Umuarama - PR. ${ }^{5}$ Professora do Departamento de Medicina Veterinária - Universidade Federal do Paraná. ${ }^{6}$ Alunas do Curso de Pós-Graduação em Ciências Veterinárias - Universidade Federal do Paraná. ${ }^{7}$ Acadêmicos do Curso de Medicina Veterinária - Universidade Federal do Paraná. ${ }^{8}$ Aluna do Curso de Pós-Graduação em Biologia Celular - Universidade Federal do Paraná.

Com o objetivo de estabelecer parâmetros laboratoriais de referência para a espécie caprina, foram determinadas as concentrações séricas da uréia, creatinina, aspartato aminotransferase (AST), bilirrubinas (total, direta e indireta) e fosfatase alcalina de 45 fêmeas e a concentração da gama glutamiltransferase (GGT) de 38 fêmeas adultas clinicamente sadias, das raças Saanen e Parda Alpina, criadas na Região Metropolitana de Curitiba. O material para este trabalho foi colhido de animais criados em regime intensivo, com manejo alimentar e sanitário semelhantes. As amostras sanguíneas foram obtidas por venopunção da jugular externa utilizando-se o sistema vacutainer, em tubos sem anticoagulante, e posteriormente encaminhadas ao Laboratório de Análises Clínicas do Hospital Veterinário da UFPR. As médias e os desvios padrão encontrados foram: uréia $(\mathrm{mg} / \mathrm{dl}) \rightarrow 43,4$ e 14,3; creatinina $(\mathrm{mg} / \mathrm{dl}) \rightarrow 0,7$ e 0,2; AST $(\mathrm{U} / \mathrm{l}) \rightarrow 30,2$ e 10,9; bilirrubina total $(\mathrm{mg} / \mathrm{dl}) \rightarrow 0,7$ e 0,4 ; bilirrubina direta $(\mathrm{mg} / \mathrm{dl}) \rightarrow 0,1$ e 0,1 ; bilirrubina indireta $(\mathrm{mg} / \mathrm{dl}) \rightarrow 0,6$ e 0,4 ; fosfatase alcalina $(\mathrm{UI} / \mathrm{l}) \rightarrow 91,1$ e 41,1 ; gama glutamiltransferase (U/l) $\rightarrow$ 36,5 e 9,5. Ressalta-se a importância da determinação de valores laboratoriais de referência, pois podem ser utilizados para avaliar o estado de nutrição, de alterações metabólicas e de alterações patológicas que ocorrem nas diversas enfermidades que acometem os caprinos. 